Goldschmidt 2021 Abstract

https://doi.org/10.7185/gold2021.8246

\section{Non-reductive, ligand-promoted dissolution is responsible for enhanced weathering of ferric (oxy)hydroxides in the Pine (mycor)rhizosphere}

RYAN VINCENT TAPPERO ${ }^{1}$, HUI-LING (SUNNY) LIAO ${ }^{2}$ JENNIFER BHATNAGAR ${ }^{3}$, COLIN AVERILL ${ }^{4}$, KO-HSUAN (KOKO) $\mathrm{CHEN}^{5}$, KAILE ZHANG ${ }^{2}$, ADESUWA ERHUNMWUNSE ${ }^{2}$, PAUL NORTHRUP ${ }^{6}$, TIFFANY VICTOR $^{1}$, SARAH L NICHOLAS ${ }^{1}$, LIAM MCCARTHY ${ }^{1}$ AND RYTAS VILGALYS ${ }^{7}$

${ }^{1}$ Brookhaven National Laboratory

${ }^{2}$ University of Florida

${ }^{3}$ Boston University

${ }^{4}$ ETH Zürich

${ }^{5}$ Academia Sinica

${ }^{6}$ Stony Brook University

${ }^{7}$ Duke University

Presenting Author: rtappero@bnl.gov

Iron $(\mathrm{Fe})$ is an essential plant nutrient and cofactor of numerous plant enzymes but exists in soil as sparingly-soluble minerals and coatings (e.g., oxyhydroxides). We hypothesize that biogeochemical perturbations due to ectomycorrhizal symbiosis can cause enhanced weathering of soil minerals leading to a larger pool of bioavailable nutrients for plant uptake. We used the well-established ectomycorrhizal Pinus-Suillus model symbiont system to investigate Fe dynamics across the plantmycorrhiza-soil interface. $P$. contorta seedlings were inoculated with Suillus brevipes (SB 120) and then grown for two months in a nutrient-poor sand culture supplemented with ferrihydritecoated sand. Morphological changes to roots were visibly evident for the ectomycorrhizal fungi (EMF) treatments. In-situ X-ray fluorescence (XRF) imaging revealed spatial and chemical differences between the +EMF and -EMF treatments. The PinusSuillus system contained roots with a fungal sheath enriched with iron. Microcosms lacking EMF contained predominantly unaltered grains of iron-coated sand following the 2-month growth period while those with EMF contained grains with severely altered coatings that had 'disintegrated' near roots. Time-series XRF imaging of the mycor(rhizosphere) showed an expanding interaction zone around roots. Spatially-resolved $\mathrm{Ca}$ K-edge micro- X-ray absorption spectroscopy ( $\mu \mathrm{XAS}$ ) revealed the presence of tiny Ca-oxalate crystals in the (mycor)rhizosphere and Fe K-edge $\mu$ XAS identified an Fe(III) organometallic complex associated with the fungal sheath surrounding $+\mathrm{EMF}$ roots. As a direct consequence, $P$. contorta root cortical cells are bathed continuously with $\mathrm{Fe}(\mathrm{III})$-chelators similar to ones used in hydroponics solutions. Early indications from this work are that the plant uses its Fe-reductase system to acquire $\mathrm{Fe}(\mathrm{II})$ from the pool of $\mathrm{Fe}(\mathrm{III})$-chelators at the plantmicrobe interface. Future work planned at harvest includes OMICS, bulk tissue analyses, and ex-situ imaging of radial sections to interrogate Fe speciation in root cortical cells and the Hartig net. These findings support the hypothesis that ectomycorrhizal symbiosis enhances mineral weathering and can dissolve $\mathrm{Fe}$ coatings and transform them into plant-available forms without reduction, which in turn enhances plant biomass.

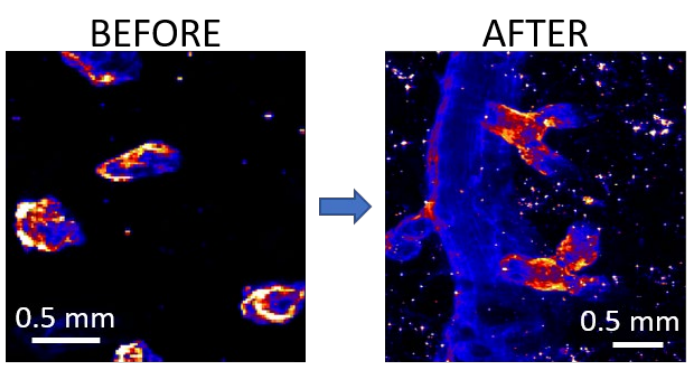

Image of iron (Fe) in model soil before and after 2 months mutualistic growth of Pinus-Suillus.

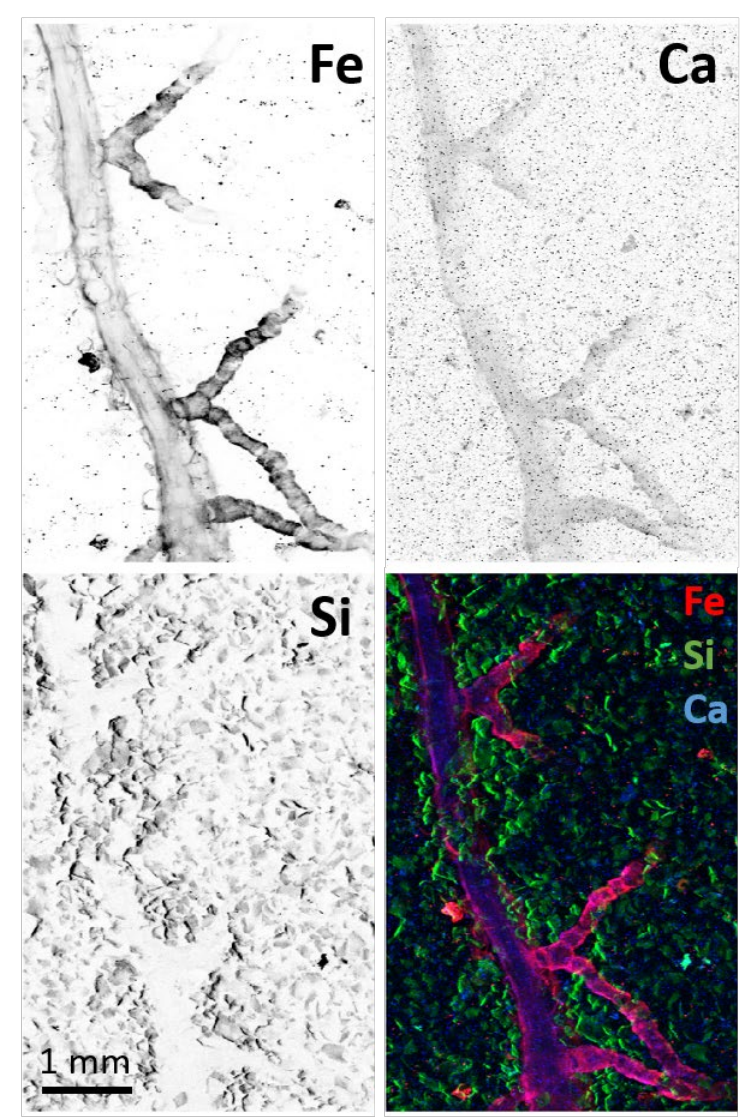

In-situ X-ray fluorescence (XRF) images of iron (Fe), silicon ( $\mathrm{Si}$ ), and calcium ( $\mathrm{Ca}$ ) in Pinus-Suillus rhizosphere after 2 months mutualistic growth. Images from the XFM Beamline at the NSLS-II. 